\title{
Rab11 is associated with GLUT4-containing vesicles and redistributes in response to insulin
}

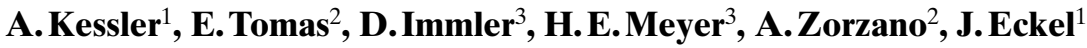 \\ ${ }^{1}$ Molecular Cardiology, Diabetes Research Institute, Düsseldorf, Germany \\ ${ }^{2}$ Department of Biochemistry and Molecular Biology, University of Barcelona, Barcelona, Spain \\ ${ }^{3}$ Institute for Physiological Chemistry, Ruhr University Bochum, Bochum, Germany
}

\section{Abstract}

Aims/hypothesis. To identify a GTPase of $24000 \mathrm{M}_{\mathrm{r}}$ which we recently found to co-localize with GLUT4 in cardiac muscle.

Methods. A $24000 \mathrm{M}_{\mathrm{r}}$-GTP-binding fraction was purified from pig heart by a three-step chromatographic procedure, followed by two-dimensional electrophoresis and electrospray ionization-mass spectrometry. Subcellular distribution of the GTPase was assessed by western blotting. Co-localization with GLUT4 was assessed by continuous sucrose density gradient fractionation and immunoadsorption of GLUT4-containing vesicles.

Results. The Rab11 protein was identified as a major component of the GTP-binding fraction and its expression in rat cardiac muscle was confirmed. In vivo insulin treatment resulted in the recruitment of Rab11 from the microsomal fraction to the plasma membrane. Subcellular fractionation indicated two immunoreactive GLUT4 pools. Most of the intracellular pool of Rab11 overlapped with the high-density
GLUT4 pool and most of the transferrin receptor pool. The Rab11 protein also co-sedimented with the low-density, non-endosomal GLUT4 pool and substantially increased in this fraction after insulin treatment. It was specifically present in GLUT4-containing vesicles and insulin increased its abundance in these vesicles 2.2-fold relative to the amount of GLUT4. These vesicles also containend Rab4 and Akt-2, the latter being only associated after insulin stimulation. Insulin was unable to alter the cellular localization of Rab11 in insulin-resistant obese Zucker rats.

Conclusion/interpretation. These results support the hypothesis that at least two GTPases of the Rab family participate in GLUT4-vesicle trafficking. We suggest that Rab11 is involved in the endosomal recycling, sorting and exocytotic movement of the glucose transporter. [Diabetologia (2000) 43: 1518-1527]

Keywords GLUT4 trafficking, Rab11, cardiac muscle, GLUT4-containing vesicles, small GTP-binding proteins, Zucker rats.
Homeostasis of blood glucose by insulin involves the rapid and large stimulation of glucose uptake by muscle and adipose tissue. This important action of the

Received: 24 May 2000 and in revised form: 18 July 2000

Corresponding author: Dr. J. Eckel, Diabetes Research Institute, Auf'm Hennekamp 65, D-40225 Düsseldorf, Germany Abbreviations: PI 3-kinase, Phosphatidylinositol 3-kinase; PM, plasma membrane fraction; MM, microsomal membrane fraction; GTP $\gamma$ S, guanosine 5'-O-(3-thiotriphosphate); DTT, dithiothreitol; PVDF, polyvinylidene difluoride; VAMP, vesicle-associated membrane protein; ECL, enhanced chemiluminescence. hormone is based on the translocation of the glucose transporter isoform GLUT4 from an intracellular pool to the cell surface [1,2]. A major aspect of this process that is still to be defined is that of the downstream signalling from the insulin receptor to the GLUT4 compartment and how these signals trigger recruitment of the GLUT4-containing vesicles to the plasma membrane. To explain these processes, several laboratories have isolated the intracellular vesicles containing GLUT4 and characterized their protein composition [3-9]. In addition to GLUT4, three major companion proteins have been identified in GLUT4-containing vesicles including an insulin-reg- 
ulated aminopeptidase (IRAP), the insulin-like growth factor II/mannose 6 -phosphate receptor and sortilin $[1,4,6,7]$. These proteins, which have extracellular functional domains, are considered as "cargo" proteins most probably exerting functions different from GLUT4-translocation [1]. Members of the VAMP (vesicle-associated membrane protein) family have also been detected in vesicles containing GLUT4 $[8,10]$ and according to the SNARE (soluble $\mathrm{N}$-ethylmaleimide-sensitive factor-attachment protein receptor) hypothesis, syntaxin 4, VAMP2 or VAMP3 or both are thought to mediate the docking and fusion of GLUT4-containing vesicles at the plasma membrane $[2,11]$. Recently, phosphatidylinositol 3-kinase (PI 3-kinase) and Akt-2 (PKB $\beta)$, two elements of the insulin signalling cascade, were also shown to co-localize with GLUT4 $[5,9,12]$. Coupling of these lipid and protein kinases to the translocation machinery has not, however, been defined.

A family of Ras-related Rab GTP-binding proteins has been implicated in the regulation of intracellular vesicular traffic [13] and Rab GTPases have been localized to distinct intracellular compartments along the exocytotic and endocytotic pathways, suggesting specialized transport functions of the different Rab proteins [14]. More than thirty different Rab GTPases have been described but until now only Rab4 was shown to be involved in GLUT4 translocation [15-19]. Thus, it has been reported that Rab4 is associated with GLUT4-containing vesicles and redistributes in response to insulin [15]. Further, microinjection of Rab4 antibodies [16] and peptides against the hypervariable carboxy-terminal domain [17] were shown to inhibit insulin-induced GLUT4 translocation. Functional implication of Rab4 in GLUT4 trafficking was recently confirmed by overexpression in adipocytes [18] and myocytes [19] and by heterologous expression of Rab4 and GLUT4 in Xenopus oocytes [20]. These studies showed, however, that Rab4 participates in the intracellular sequestration of GLUT4 and the biogenesis of the GLUT4 storage compartment but most probably not in the exocytotic movement to the plasma membrane $[18,19]$.

In our earlier studies [21, 22] we reported that a GTPase of $24000 \mathrm{M}_{\mathrm{r}}$ different from Rab4 is associated with GLUT4-containing vesicles isolated from rat cardiac muscle. In the present investigation a purification strategy was developed with the ultimate aim of identifying this protein. We now report that cardiac microsomes express an appreciable amount of Rab11 with a redistribution to the plasma membrane in response to insulin. Further, Rab11 is associated with GLUT4-containing vesicles and after in vivo insulin treatment an increased abundance of Rab11 in the GLUT4-vesicles was observed. This effect was not detectable in insulin-resistant obese Zucker rats. We therefore conclude that Rab11 represents a new element of the GLUT4-trafficking pathways.

\section{Materials and methods}

Materials. We purchased $\left[\alpha_{-}{ }^{32} \mathrm{P}\right] \mathrm{GTP}(110 \mathrm{TBq} / \mathrm{mmol})$ and $\left[{ }^{35} \mathrm{~S}\right] \mathrm{GTP} \gamma \mathrm{S}(37 \mathrm{TBq} / \mathrm{mmol})$ from Amersham (Braunschweig, Germany). Reagents for SDS-PAGE were supplied by Pharmacia and Sigma (München, Germany). Insulin (Actrapid $\mathrm{HM} ; 100$ units/ml) was from Novo (Mainz, Germany). Horseradish peroxidase conjugate (anti-rabbit or anti-mouse $\mathrm{IgG}$ ) as secondary antibody for enhanced chemiluminescence (ECL) detection was purchased from Promega (Mannheim, Germany). The anti-Rab4 antibody was kindly provided by Dr. B. Goud (Paris, France). Monoclonal anti-transferrin receptor antibody was purchased from Zymed (San Francisco, Calif., USA) and the monoclonal Rab11 antibody was a product of Transduction Laboratories (Lexington, Ky., USA). The polyclonal antiserum against GLUT4 was obtained by immunizing rabbits with a peptide corresponding to the C-terminal 12 amino acids of GLUT4 coupled to keyhole limpet haemocyanin (Eurogentec, Belgium). All other chemicals were of the highest grade commercially available.

Purification of small GTP-binding proteins. The procedure used for purification of small GTP-binding proteins was based on protocols developed by other laboratories [23, 24]. Pig hearts obtained from freshly slaughtered pigs were placed in ice-cold PBS, pH 7.4 and were subsequently used for the preparation of a crude membrane fraction. Each step was carried out at $4{ }^{\circ} \mathrm{C}$. The cardiac ventricle (about $300 \mathrm{~g}$ ) was cut in small pieces and homogenized in a buffer containing $10 \mathrm{mmol} / \mathrm{l}$ TRIS/HCl, pH 7.4, 0.1 phenylmethyl-sulphonyl fluoride and $2.6 \mathrm{mmol} / \mathrm{l}$ dithiothreitol by using an Ultra-Turrax (Ika, NeuIsenburg, Germany) for $100 \mathrm{~s}$. Homogenization was continued by 6 strokes $(1300 \mathrm{rpm})$ in a glass-Teflon homogenizer and the homogenate was filtered through wide-meshed gauze. After centrifugating at $3000 \cdot g$ for $15 \mathrm{~min}$, the supernatant was centrifuged at $180000 \cdot \mathrm{g}$ for $100 \mathrm{~min}$ to pellet the crude membrane fraction.

For extracting GTP-binding proteins, the crude membrane was diluted $1: 2$ with a $20 \mathrm{mmol} / \mathrm{l} \mathrm{TRIS} / \mathrm{HCl}$ buffer, $\mathrm{pH} 8.0$, containing $1 \mathrm{mmol} / \mathrm{l}$ EDTA, $1 \mathrm{mmol} / \mathrm{l}$ dithiothreitol (DTT), $1 \mathrm{umol} / 1$ phenylmethylsulphonyl fluoride and $125 \mathrm{mmol} / \mathrm{l}$ $\mathrm{NaCl}$ and centrifuged at $200000 \cdot \mathrm{g}$ for $90 \mathrm{~min}$. The pellet was resuspended in the same buffer containing $4.5 \%$ sodium cholate instead of $\mathrm{NaCl}$ followed by incubation for $1 \mathrm{~h}$ under continuous stirring. Unsoluble material was removed by centrifugating at $100000 \cdot g$ for $1 \mathrm{~h}$, solubilized proteins were collected and $\mathrm{MgCl}_{2}$ was added at a final concentration of $5 \mathrm{mmol} / \mathrm{l}$.

About $12 \mathrm{ml}$ (51 mg protein) of the total cholate extract (108 ml, $464 \mathrm{mg}$ protein) was applied using nine different runs to a Hi PrepSephacryl column (Pharmacia, Freiburg, Germany) which was equilibrated with 2 column volumes of buffer (20 mmol/1 TRIS/HCl pH 8.0, $1 \mathrm{mmol} / 1$ EDTA, $1 \mathrm{mmol} / 1$ DTT, $5 \mathrm{mmol} / \mathrm{l} \mathrm{MgCl}_{2}, 1 \%$ sodium cholate and $100 \mathrm{mmol} / \mathrm{l}$ $\mathrm{NaCl}$ ). Proteins were eluted with the same buffer at a flow rate of $60 \mathrm{ml} / \mathrm{h}$ and fractions of $5 \mathrm{ml}$ were collected. These fractions were subjected to a $\left[{ }^{35} \mathrm{~S}\right] \mathrm{GTP}$-binding assay showing two peaks of GTP-binding activity. The active fractions of the second were pooled and applied to a Phenyl Sepharose High Performance column to separate the proteins in relation to their hydrophobic properties. The column was equilibrated with $1200 \mathrm{ml}$ of $20 \mathrm{mmol} / \mathrm{l} \mathrm{TRIS} / \mathrm{HCl}, \mathrm{pH} 8.0,1 \mathrm{mmol} / \mathrm{l}$ EDTA, $1 \mathrm{mmol} / \mathrm{l} \mathrm{DTT}$ and $5 \mathrm{mmol} / 1 \mathrm{MgCl}_{2}$ and afterwards with the same buffer adding $0.2 \%$ sodium cholate and $250 \mathrm{mmol} / \mathrm{l}$ $\mathrm{NaCl}$ in a buffer volume of $600 \mathrm{ml}$. The pooled fractions from the first column were diluted in the latter buffer to a concentration of $90 \mu \mathrm{g} / \mathrm{ml}$ and applied to the Phenyl Sepharose column. The elution was done with a dual gradient of sodium cho- 
late $(0.2 \%-1.3 \%)$ and $\mathrm{NaCl}(250-25 \mathrm{mmol} / \mathrm{l})$ in $20 \mathrm{mmol} / \mathrm{l}$ TRIS/HCl pH 8.0, $1 \mathrm{mmol} / \mathrm{l}$ EDTA, $1 \mathrm{mmol} / \mathrm{l}$ DTT, $5 \mathrm{mmol} / \mathrm{l}$ $\mathrm{MgCl}_{2}$ with a flow rate of $120 \mathrm{ml} / \mathrm{h}$. Fractions of $5 \mathrm{ml}$ were collected and tested for GTP-binding by ligand blotting.

Fractions with GTP-binding activity were pooled, diluted to $0.1 \mathrm{mg} / \mathrm{ml}$ with $20 \mathrm{mmol} / 1 \mathrm{TRIS} / \mathrm{HCl} \mathrm{pH} 8.0,1 \mathrm{mmol} / \mathrm{l} \mathrm{DTT}$ and applied to a hydroxyapatite column (Econo-Pac CHT-II Cartridge, BioRad, Hercules, Calif., USA), previously equilibrated with $100 \mathrm{ml}$ of $20 \mathrm{mmol} / \mathrm{TRIS} / \mathrm{HCl} \mathrm{pH} 8.0,0.1 \mathrm{~mol} / \mathrm{l}$ EDTA, $1 \mathrm{mmol} / \mathrm{l}$ DTT, $3 \mathrm{mmol} / 1 \mathrm{MgCl}_{2}$ and $10 \mathrm{mmol} / \mathrm{l}$ $\mathrm{KH}_{2} \mathrm{PO}_{4}$. Sample components were selectively eluted from the cartridge by running a gradient from $10 \mathrm{mmol} / \mathrm{KH}_{2} \mathrm{PO}_{4}$ to $400 \mathrm{mmol} / 1 \mathrm{KH}_{2} \mathrm{PO}_{4}$ in $20 \mathrm{mmol} / \mathrm{l} \mathrm{TRIS} / \mathrm{HCl} \mathrm{pH} 8.0$, $0.1 \mathrm{mmol} / \mathrm{l}$ EDTA, $1 \mathrm{mmol} / \mathrm{l} \mathrm{DTT}, 3 \mathrm{mmol} / 1 \mathrm{MgCl}_{2}, 0.6 \% 3-$ [(3-cholamido-propyl)dimethylammonio]-1-propanesulphonic acid (CHAPS) with a volume of $200 \mathrm{ml}$ and a flow rate of $30 \mathrm{ml} / \mathrm{h}$. Fractions having a signal after ligand blotting with $\left[{ }^{32} \mathrm{P}\right] \mathrm{GTP}$ at a size of $24000 \mathrm{M}_{\mathrm{r}}$ were pooled and run in a twodimensional PAGE.

$\left[{ }^{35} S\right] G T P \gamma S$-binding assay. Binding of $\left[{ }^{35} \mathrm{~S}\right] \mathrm{GTP} \gamma \mathrm{S}$ was measured by incubating the collected fractions in a buffer containing $20 \mathrm{mmol} / \mathrm{l} \mathrm{TRIS} / \mathrm{HCl}, \mathrm{pH} 7.5,1 \mathrm{mmol} / \mathrm{l}$ EDTA, $5 \mathrm{mmol} / \mathrm{l}$ $\mathrm{MgCl}_{2}, \quad 200 \mathrm{mmol} / \mathrm{l} \mathrm{NaCl}, 1 \mathrm{mmol} / \mathrm{l}$ DTT and $37 \mathrm{kBq}$ $\left[{ }^{35} \mathrm{~S}\right] \mathrm{GTP} \gamma \mathrm{S}$ (final concentration $10 \mathrm{nmol} / \mathrm{l}$ ) in a final volume of $100 \mu \mathrm{l}$ at $25^{\circ} \mathrm{C}$. After $40 \mathrm{~min}$, the reaction was ended by the addition of $2 \mathrm{ml}$ ice-cold stop solution $(20 \mathrm{mmol} / \mathrm{l}$ TRIS, $\mathrm{pH}$ $7.5,200 \mathrm{mmol} / \mathrm{l} \mathrm{NaCl}, 25 \mathrm{mmol} / \mathrm{I} \mathrm{MgCl}_{2}$ ) followed by rapid filtration through B85 nitrocellulose filters (Schleicher \& Schuell, Dassel, Germany). The filters were washed with $6 \mathrm{ml}$ stop solution, dried and placed into $8 \mathrm{ml}$ of scintillation fluid. Radioactivity was measured in a Beckman LS 6000 IC scintillation counter. All experiments were done in triplicate. Nonspecific binding was monitored in parallel incubations in the presence of $100 \mu \mathrm{mol} / \mathrm{l}$ unlabelled GTP.

Ligand blotting of small GTP-binding proteins. Protein samples were subjected to one-dimensional SDS-PAGE using 8-18\% horizontal gels. Proteins were transferred to a polyvinylidene difluoride (PVDF) membrane (Millipore, Bedford, Mass., USA) in a semi-dry blotting apparatus and GTP binding to proteins was assessed as described previously [25]. Blots were preincubated for $10 \mathrm{~min}$ in a buffer containing $50 \mathrm{mmol} / \mathrm{l}$ TRIS/HCl, pH 7.5, 0.3\% Tween 20 and $2 \mu \mathrm{mol} / 1 \mathrm{MgCl}_{2}$. Incubation was continued in the same buffer containing $[\alpha$ $\left.{ }^{32} \mathrm{P}\right] \mathrm{GTP}(37 \mathrm{kBq} / \mathrm{ml}), 1 \mathrm{nmol} / \mathrm{l} \mathrm{GTP}$ and $10 \mu \mathrm{mol} / \mathrm{l}$ ATP for $30 \mathrm{~min}$ at room temperature. After washing the blots for $30 \mathrm{~min}$ with the preincubation buffer, they were air-dried and subjected to autoradiography and analysed on a FUJIX BAS 1000 bio-imaging analyser (Fuji, Tokyo, Japan).

Two-dimensional polyacrylamid gel electrophoresis and mass spectrometry. Two-dimensional PAGE was done as described previously [26] with modifications. For isoelectric focussing, Immobiline Dry Strip gels (Pharmacia, Freiburg, Germany) were used that had an immobilized $\mathrm{pH}$ gradient of 3.0-10.0. Electrophoresis was carried out for $8 \mathrm{~h}$ at $300 \mathrm{~V}$ and $10 \mathrm{~h}$ at 2 $\mathrm{kV}$. After focussing was completed, strips were applied to a horizontal SDS-PAGE using a $12 \%$ gel. Proteins were transferred to a PVDF membrane in a semi-dry blotting apparatus and GTP-binding to proteins was measured as described above.

After destaining the coomassie-stained gel, the gel pieces were washed twice in digestion buffer $\left(10 \mathrm{mmol} / \mathrm{l} \mathrm{NH} \mathrm{NCO}_{3}\right)$ for $15 \mathrm{~min}$ and also twice for $15 \mathrm{~min}$ in digestion buffer/acetonitrile 1:1. Gels were then incubated overnight in protease solution (trypsin at $0.05 \mu \mathrm{g} / \mu \mathrm{l}$ in digestion buffer) at $37^{\circ} \mathrm{C}$. The supernatant was collected and dried down to about $0.5 \mu \mathrm{l}$. For nanospray-electrospray ionization, $2 \mu \mathrm{l}$ of $70 \%$ formic acid was added and this solution was used in $0.5 \mu$ l aliquots. Mass spectrometry was done using a TSQ 7000 triple quadrupole mass spectrometer (Finnigan MAT, San Jose, Calif., USA). Data acquisition and evaluation was done on a DEC 3000 workstation using the ICIS software, version 8.2.1. [27]. Peptide mass calculation was done with the BIOWORKS software, version 8.2.1. [27].

For the fully automatic interpretation of fragment ion spectra the SEQUEST algorithm (version B22) [28, 29] was used. A 'homo sapiens' subset of the OWL protein database (version from August 15, 1997, 198742 entries) was used as database. The search variables were: mass tolerance of $1000 \mathrm{M}_{\mathrm{r}}$ for the parent ion, tryptic digest, oxidation of methionine and carbamidomethylation of cysteine as different modifications. The weighting of the different ion series was as follows: neutral loss ions of A-series and B-series $1, b$-ions and $\gamma$-ions 1 and $a$ ions 0.5 .

Subcellular fractionation of cardiac ventricular tissue. We used male Wistar rats (weighing 280-320 g) or genetically obese ( $f a / f a)$ Zucker rats (weighing 480-520 g) that were given free access to food, in these experiments. Plasma membrane (PM) and microsomal membrane (MM) fractions from cardiac muscle of Wistar and Zucker rats were prepared as described previously $[22,30]$. Briefly, ventricular tissue was removed and homogenized in a buffer containing $10 \mathrm{mmol} / \mathrm{l} \mathrm{TRIS} / \mathrm{HCl}$, $0.1 \mathrm{mmol} / \mathrm{l}$ phenylmethylsulphonyl fluoride and $2.6 \mathrm{mmol} / \mathrm{l}$ DTT by using an Ultra-Turrax (Ika, Neu-Isenburg, Germany) for $60 \mathrm{~s}$. Homogenization was continued by 10 strokes in a glass-Teflon homogenizer, followed by $3 \cdot 3$ strokes in a tightfitting Potter-Elvehjem homogenizer. After centrifugating at $3000 \cdot g$ for $10 \mathrm{~min}$, the supernatant was centrifuged at $200000 \cdot g$ for $90 \mathrm{~min}$ to pellet the crude membrane fraction and to obtain the cytosol in the supernatant. Further purification was achieved by applying this fraction to a discontinuous gradient consisting of $0.57,0.72,1.07$ and $1.43 \mathrm{~mol} / 1$ sucrose in the above buffer and centrifugated at $40000 \cdot \mathrm{g}$ for $16 \mathrm{~h}$. Membranes were harvested from each sucrose layer and stored at $-70^{\circ} \mathrm{C}$. Protein was measured by a modification of the BioRad protein assay with BSA as a standard. To fractionate crude membranes in a $10-35 \%(w / v)$ continuous sucrose-density gradient, the crude membranes $(10 \mathrm{mg}$ of protein) were suspended in the above buffer, loaded on the gradient and centrifuged for $16 \mathrm{~h}$ in a SW-60 rotor at $40000 \cdot \mathrm{g}$. Plasma membranes were removed by collecting the material floating on top of the gradient plus a volume of $400 \mu \mathrm{l}$ of the upper layer of the gradient. Fractions of $200 \mu \mathrm{l}$ were then collected from the top of the tube to the bottom and analysed. For insulinstimulation studies, rats received a tail-vein injection of regular insulin (4 units/ $100 \mathrm{~g}$ body weight) and hearts were removed 20 min later.

Immunoblotting. Proteins were separated by SDS-PAGE using Excel 8-18\% gels (Pharmacia, Freiburg, Germany) or $9 \%$ and $12 \%$ polyacrylamide gels, as described previously [31] and transferred to a PVDF membrane in a semi-dry blotting apparatus. The membrane was blocked with $5 \%$ non-fat dry milk in PBS, pH 7.4 containing $0.05 \%$ Tween 20 for $1 \mathrm{~h}$ at room temperature and incubated with different antibodies overnight at $4{ }^{\circ} \mathrm{C}$ afterwards. After washing the membrane with PBS containing $0.05 \%$ Tween 20 , detection was carried out by incubating the membrane with a horseradish peroxidase-conjugated goat anti-rabbit or anti-mouse antiserum as a secondary antibody. After several washing steps, the membrane was developed by enhanced chemiluminescence using SuperSignal Sub- 


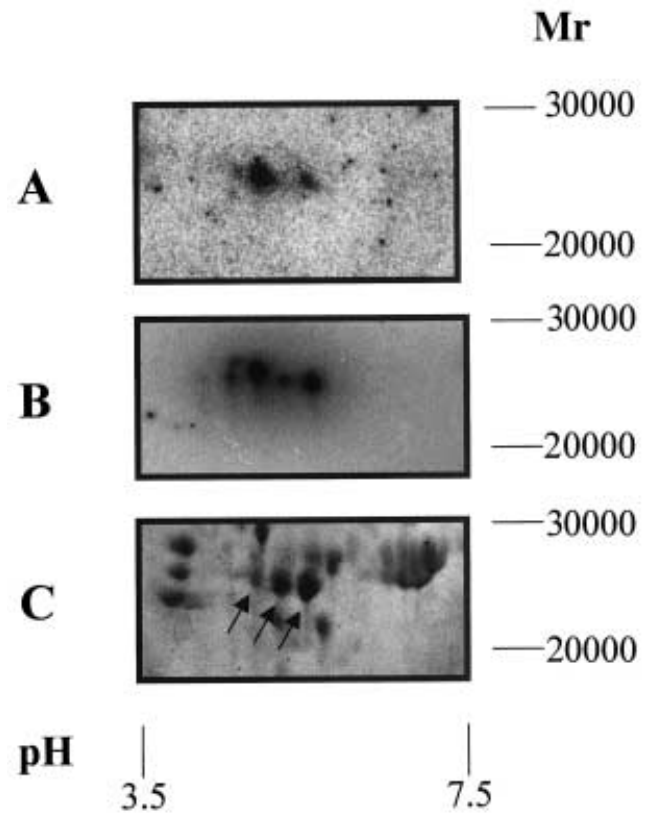

Fig.1A-C. Labelling of small GTP-binding proteins with $[\alpha-$ ${ }^{32} \mathrm{P}$ ] GTP in GLUT4-containing vesicles and fractions obtained from hydroxyapatite chromatography. A GLUT4-containing vesicles immunoadsorbed from cardiac microsomal membranes $(500 \mu \mathrm{g})$ and $\mathbf{B}$ portions $(8.5 \mu \mathrm{l})$ of the concentrated fractions of hydroxyapatite chromatography were subjected to isoelectric focussing followed by SDS-PAGE. After blotting the PVDF sheet was incubated with $\left[\alpha-{ }^{32} \mathrm{P}\right] \mathrm{GTP}$, washed and autoradiographed. C $85 \mu \mathrm{l}$ of the concentrated column fractions was applied to two-dimensional PAGE and the proteins were visualized by staining the gel with Coomassie blue. Spots marked with an arrow were subjected to analysis by mass spectrometry

strate (Pierce, Rockford, Ill., USA), then visualized and evaluated on a LUMI Imager (Boehringer Mannheim, Mannheim, Germany). Significance of reported differences was evaluated by using the null hypothesis and $t$ statistics for unpaired data. A $p$ value less than 0.05 was considered to be statistically significant.

Immunoadsorption of GLUT4-containing vesicles. Protein Apurified monoclonal anti-GLUT4 antibody (1F8) or a corresponding amount of non-specific antibodies ( $\gamma$-globulins) was coupled to acrylamide beads (Reacti-gel GF 2000, Pierce) at a concentration of $1 \mathrm{mg}$ of antibody/ml of resin according to the manufacturer's instructions. Microsomal membranes were incubated with beads overnight at $4^{\circ} \mathrm{C}$ as reported [32]. The beads were spun down and washed five times with PBS. The adsorbed material was eluted with Laemmli sample buffer and half of this eluted volume was subjected to SDS-PAGE.

\section{Results}

Purification and identification of a small GTP-binding protein from cardiac muscle. We have recently described a $24000 \mathrm{M}_{\mathrm{r}}$-GTP-binding protein in rat cardiac muscle that co-localizes to GLUT4 [21]. In an attempt to purify this protein we used a crude mem- brane fraction from pig heart after confirming the presence of the GTPase of $24000 \mathrm{M}_{\mathrm{r}}$ in GLUT4-vesicles immunoadsorbed from this material. Solubilized proteins were first applied to a gel filtration column to separate $G_{\alpha}$ subunits of heterotrimeric $G$ proteins from small GTP-binding proteins. Fractions with GTP-binding activity of an estimated molecular mass of 20000-30000 $\mathrm{M}_{\mathrm{r}}$ were applied to a second column using hydrophobic interaction chromatography. Aliquots of the eluted material were subjected to ligand blotting with $\left[\alpha-{ }^{32} \mathrm{P}\right] \mathrm{GTP}$, where a specific labelling of small GTP-binding proteins with 24000 $\mathrm{M}_{\mathrm{r}}$ and $26000 \mathrm{M}_{\mathrm{r}}$ could be detected (data not shown). Fractions containing both the species with $24000 \mathrm{M}_{\mathrm{r}}$ and $26000 \mathrm{M}_{\mathrm{r}}$ were pooled and applied to the final column. This hydroxyapatite column made it possible to separate $24000 \mathrm{M}_{\mathrm{r}}$ and $26000 \mathrm{M}_{\mathrm{r}}$ proteins. Fractions having GTP-binding at $24000 \mathrm{M}_{\mathrm{r}}$ were then pooled and concentrated.

The final step of our purification consisted in the application of the fraction with $24000 \mathrm{M}_{\mathrm{r}}$ to a high resolution two-dimensional gel electrophoresis with subsequent analysis by $\left[\alpha-{ }^{32} \mathrm{P}\right] \mathrm{GTP}$ overlay (Fig.1B). For direct comparison, GLUT4-containing vesicles immunoadsorbed from cardiac microsomes were analysed in parallel (Fig. 1A). At least five major spots with an isoelectric point between 5.0 and 6.0 could be detected in the final column fractions. Part of these signals correlated well with the GTPbinding proteins detected in the GLUT4-containing vesicles (Fig. 1 A). By comparing ligand blotted gel to the Coomassie-stained gel, three spots (see arrows in Fig. 1C) were selected for a further analysis. Spots were subjected to an in-gel digestion followed by elution of the resulting peptides and finally analysed by electrospray ionization-mass spectrometry [27]. For interpretation of fragment ion spectra the genbank research with SEQUEST was used. It turned out that these three signals contained two major proteins detectable by this kind of analysis: (1) mitochondrial thioredoxin-dependent peroxide reductase precursor (SP-22 protein) and (2) Rab11.

Subcellular distribution of Rab11. In the light of the identification of Rab11 in cardiac muscle, we first studied the cellular localization of Rab11 in this tissue and the potential redistribution in response to insulin under in vivo conditions. Subcellular fractions were prepared, resolved by SDS-PAGE and immunoblotted with a monoclonal anti-Rab11 antibody (Fig. 2). We found Rab11 to be most abundant in the MM fraction and to a lower extent to be also present in the plasma membrane. Insulin induced a small but statistically significant decrease of Rab11 in the MM fraction by $17 \pm 5 \%(n=4)$ (Fig. 2$)$. This decrease in the MM fraction was paralleled by a two-fold increase in Rab11 abundance in the PM fraction after insulin stimulation (Fig.2), most likely reflecting the 
A

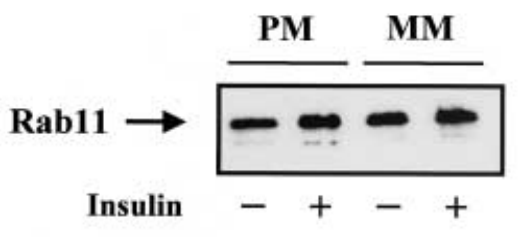

Fig.2 A, B. Subcellular localization of Rab11 and redistribution in response to insulin. A Subcellular fractions were prepared from cardiac ventricle of basal and insulin-treated rats. $20 \mu \mathrm{g}$ of plasma membranes (PM) and microsomal membranes (MM) were analysed by SDS-PAGE, transferred to PVDF and immunoblotted for Rab11. Bands were detected by using ECL system and LUMI Imager analyser. B Quantification was done by using LUMI Imager software with the amount of basal set to $100 \%$. Data are mean values \pm SEM of four separate experiments. * Significantly different from basal at $p<0.05$. $\square$ basal, $\square$ insulin

much higher absolute abundance of Rab11 in the MM fraction. We also detected Rab11 in the cytosolic fraction with marginal alterations in response to insulin (data not shown).

Co-localization of GLUT4 and Rab11. It has already been shown that Rab11 localizes to different vesicle compartments. As previously reported, this small GTP-binding protein is present in sorting endosomes and recycling compartments $[33,34]$ as well as in the trans-Golgi network [35] and post-Golgi secretory vesicles [36]. To assess the possible relation of Rab11 to translocation of GLUT4, we fractionated crude membranes from basal and insulin-stimulated hearts in a continuous sucrose density gradient. The fractionation procedure resulted in the separation of two immunoreactive GLUT4 pools, which were both sensitive to insulin (Fig.3). Most of the intracellular pool of Rab11 overlapped with the high-density GLUT4 pool and with most of the transferrin receptor pool, a generally accepted marker of the endosomal recycling compartment (Fig.3). We found, however, Rab11 at least partly co-sedimented with the lowdensity non-endosomal GLUT4 pool and substantially increased in this fraction after insulin treatment with a parallel decrease in the endosomal fraction (Fig. 3).

Direct evidence for the co-localisation of Rab11 and GLUT4 was then obtained by immunoadsorption of GLUT4-containing vesicles from cardiac microsomal membranes. We could clearly detect Rab11 in GLUT4-vesicles after immunoisolation (Fig. 4). In vivo stimulation with insulin for $20 \mathrm{~min}$ reduced the abundance of GLUT4-containing vesicles in the intracellular pool by $44 \%$ with a parallel in-

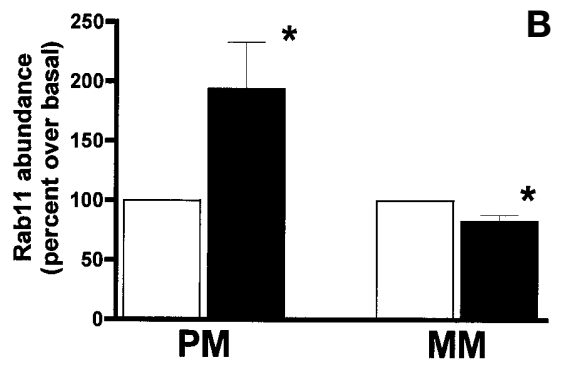

crease of Rab11 in GLUT4-vesicles (38 $\pm 6 \%$, $p<0.0014, n=3$ ) (Fig. 4). Quantification of western blots (Fig. 4) indicated that the abundance of Rab11 relative to the amount of GLUT4 increased 2.2-fold in response to insulin. To further characterize our GLUT4-vesicle preparation and provide additional support for the reliability of the Rab11 results, we assessed the GLUT4-vesicles for the presence of Rab4 and Akt-2, two proteins previously described to colocalize to GLUT4 [9, 12, 15]. We found that GLUT4-vesicles containing Rab11 also contained Rab4, with a decrease after stimulation with insulin that mostly reflected the decrease in GLUT4 (Fig. 4). These data also show the different quality of our cardiac GLUT4-vesicle preparation because we were unable to detect Rab4 using our previously published procedures [21]. In the basal state Akt-2 seems to be almost absent from GLUT4-containing vesicles but it greatly increased after stimulation with insulin, as described for rat adipocytes [9]. These data show that vesicles containing GLUT4 also contain at least two small GTPases with a different response to insulin.

Subcellular distribution of Rab11 in cardiac muscle of obese Zucker rats. Earlier work from our laboratory showed that cardiac insulin resistance in obese Zucker rats involves a defective recruitment of GLUT4 from the microsomal fraction [22]. We therefore investigated the redistribution of Rab11 in response to insulin using this animal model to gain further evidence for the relation between Rab11 and GLUT4 translocation. In contrast to Wistar rats (Fig. 2), insulin was found to be completely unable to alter the subcellular localization of Rab11 in obese Zucker rats (Fig. 5). Immunoadsorption experiments indicated the profound resistance of the intracellular GLUT4 pool towards insulin (Fig.5) in agreement with our earlier studies [22]. We found Rab11 in the GLUT4-containing vesicles but it was not responsive to insulin (Fig. 5).

\section{Discussion}

Members of the Rab family of small GTPases have been recognized as having a pivotal role for intracellular vesicular traffic with highly specialized func- 
A

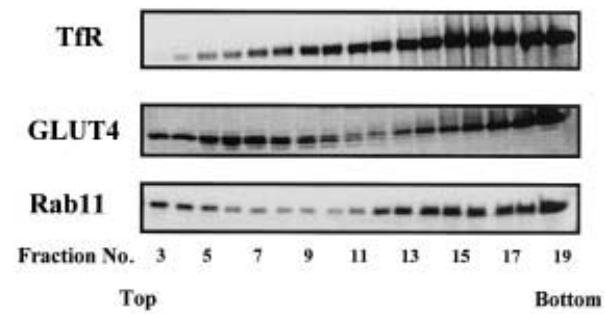

Top

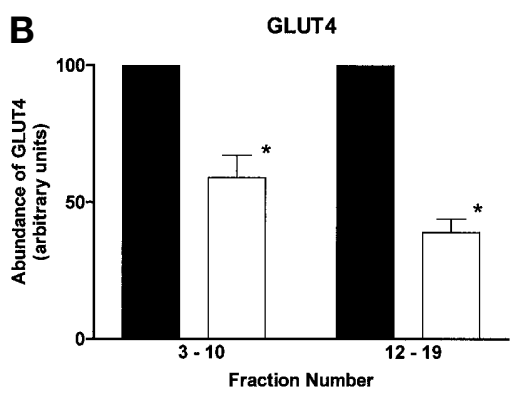

Fig.3 A, B. Fractionation of rat heart crude membranes in a continuous sucrose-density gradient. A Crude membranes (10 $\mathrm{mg}$ of protein) obtained from basal and insulin-stimulated hearts were fractionated in a $10-35 \%$ continuous sucrose gradient. Fractions $(200 \mu \mathrm{l})$ were collected and aliquots $(30 \mu \mathrm{l})$ were subjected to SDS-PAGE, followed by immunoblotting for the transferrin receptor (TfR), GLUT4 and Rab11. Representative blots out of four separate experiments are shown. B Quantification of western blots was done by using LUMI Imager software, where the amount of basal was assigned to $100 \%$. Signal intensities in fractions 3-10 and 12-19 were individually quantified and subsequently pooled. Data are mean values \pm SEM of three separate experiments. ${ }^{*} p<0.05$. $\square$ basal, $\square$ insulin

tions of the different Rab proteins [13, 14]. Earlier studies supported the notion that small GTP-binding proteins are also involved in the trafficking of GLUT4 [21, 37] but only Rab4 has been identified as being associated with GLUT4-containing vesicles [15] and functionally related to GLUT4 translocation $[18,19]$ in both adipocytes and myocytes. We now report that in addition to Rab4, Rab11 co-localizes with GLUT4 in the basal state. Furthermore, insulin increases the abundance of Rab11 in the GLUT4-containing vesicles and redistributes this protein to the plasma membrane. We therefore conclude that Rab11 participates in GLUT4 trafficking and insulin-regulated GLUT4 translocation, at least in the heart.

Cardiac muscle expresses a variety of small GTPbinding proteins with a molecular mass between 23000 and $29000 \mathrm{M}_{\mathrm{r}}$ [38]. Of the Rab family three members, Rab3C, Rab4 and Rab5 [21, 39, 40] have been observed in the rat heart, whereas Rab1A,
+ Insulin
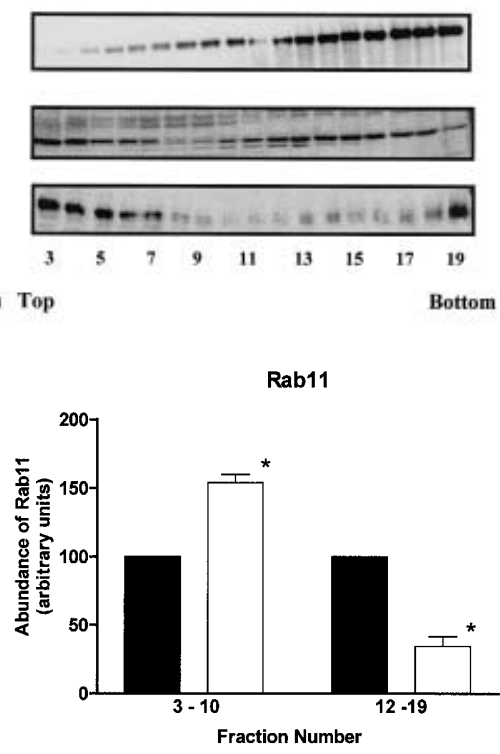

Rab2, Rab6 and Rab8 were expressed below the detection level [21, 39]. A low protein expression of Rab11 in cardiac muscle was observed when analysing homogenates of different tissues [41]. We now report the purification of a $24000 \mathrm{M}_{\mathrm{r}}$ GTP-binding protein fraction from pig heart and the identification of Rab11 as a major component of this fraction based on two-dimensional electrophoresis and mass spectrometry. Most recently, the presence of Rab11 was also observed in subcellular fractions obtained from 3T3-L1 adipocytes [42]. In these cells no effect of insulin on the distribution of both Rab4 and Rab11 became, however, detectable. Involvement of Rab11 in GLUT4 trafficking is suggested by the known function of this GTPase, which was shown to include the regulation of vesicular traffic through the recycling endosome $[33,34]$ and the transport from the transGolgi network to the plasma membrane [35, 36]. Using sucrose-density gradient centrifugation, we show here that in cardiac muscle the majority of Rab11 is present in the endosomal transferrin receptor recycling compartment, overlapping with the endosomal GLUT4 pool. The twofold increase of Rab11 at the cell surface agrees well with the translocation of two other companion proteins of GLUT4 in 3T3-L1 adipocytes, sortilin and the transferrin receptor [7], whereas the translocation of GLUT4 in response to insulin is much more pronounced, both in adipocytes and cardiac muscle [22]. This could reflect the differential effects of insulin on the rate constants of exocytosis of the endosomal and the GLUT4-storage compartment [7]. Our data is consistent with insulin-regulated movement of Rab11 from the endosomal compartment to the plasma membrane because the intracellular pool of cardiac Rab11 substantially overlapped with the transferrin receptor recycling com- 
A
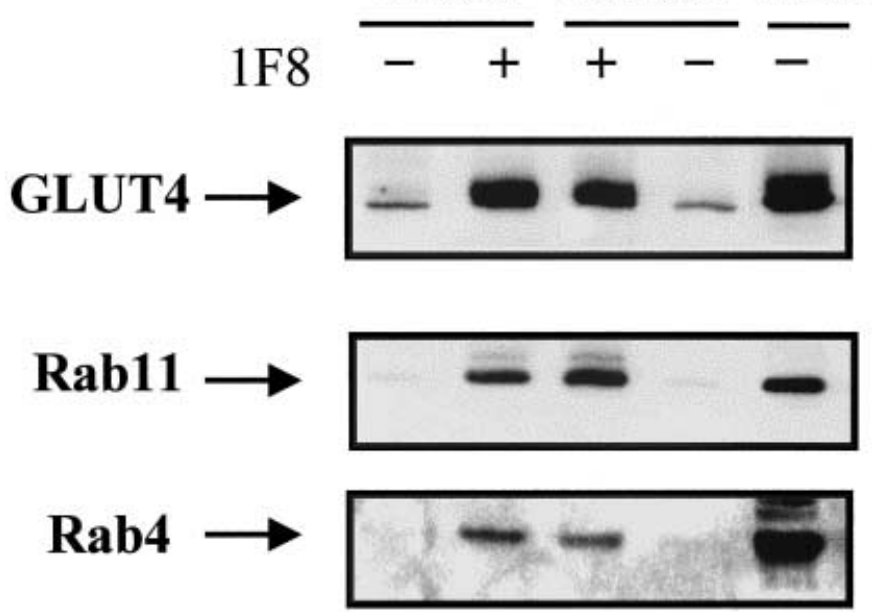

Akt-2
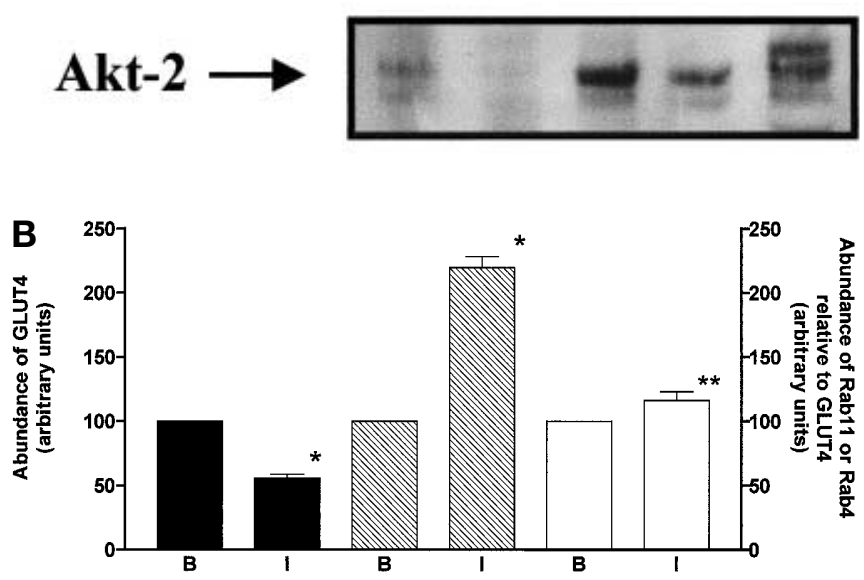

Fig.4A, B. Co-localization of Rab11, Rab4 and Akt-2 with GLUT4. A GLUT4-containing vesicles were immunoisolated from microsomal membranes of cardiac ventricular tissue of basal and insulin-stimulated rats by incubating the membranes with $(+)$ antibody $1 \mathrm{~F} 8$ coupled to acrylamide beads, or without (-) 1F8 but containing a corresponding amount of non-specific IgG-beads. Microsomal membranes $(20 \mu \mathrm{g})$ obtained from basal heart were used as a control. Samples were electrophoresed and immunoblotted for the proteins indicated. Detection was done by ECL system and LUMI Image analyser. B Quantification of western blots was done by using LUMI Imager software, where the amount of basal was assigned to $100 \%$. B, basal; I, insulin treated animals. Data are mean values \pm SEM of three separate experiments. * Significantly different from basal at $p<0.05$; ** not significantly different at $p>0.05$. Glut4, प//A Rab11, $\square$ Rab4

partment and the externalization of the transferrin receptor is known to increase about twofold in response to insulin [7]. A second pool of Rab11 with a density clearly distinct from the endosomal compartment was also detected in cardiac muscle, supporting the notion that Rab11 participates in both endosomal and non-endosomal trafficking processes [33-36]. Most notably, insulin treatment was found to shift Rab11 from the endosomal to the non-endosomal compartment. Under these conditions Rab11 completely overlapped with the non-endosomal, most likely exocytotic GLUT4 pool. These data confirm that Rab11 is an insulin-sensitive small GTP-binding protein, having a potential functional role for GLUT4 trafficking.

A key finding of our investigation is the observation that Rab11 is associated with GLUT4-containing vesicles and that this association increases in response to insulin. Combining these data with the results of our fractionation, we can conclude that insulin recruits Rab11 from the endosomal compartment to the GLUT4-containing vesicles of the exocytotic storage pool. We therefore suggest that Rab11 is involved in (i) triggering the insulin-induced movement of GLUT4 from the storage pool, or (ii) mediating the docking/fusion of GLUT4 at the plasma membrane or (i) and (ii). As recently suggested [43], the GLUT4 pathway could be related to or evolve from a ligand-independent, endosomal-recycling pathway. In this scenario Rab11 could additionally participate in the sorting of GLUT4 to a unique specialized, insulin-responsive compartment. Most recent data [42] support the notion that GLUT4 is targetted to a subpopulation of vesicles that seem to be a derivative of the endosome. The biogenesis of this compartment has been suggested to generate the pronounced insulin response of GLUT4 unique to muscle and adipose tissue [42]. It should be noted that the $24000-\mathrm{M}_{\mathrm{r}}$, GTP-binding species of GLUT4-containing vesicles described in our earlier report [21] had a decrease concomitant with GLUT4. Thus, it seems most unlikely that Rab11 is identical to this GTP-binding protein. A completely different method for immunoadsorption of GLUT4-containing vesicles was, however, used in this earlier study [21]. Further, taking into account the different sensitivity of ligand blotting [21] and western blotting (present study), it cannot be excluded that Rab11 represents at least a part of the 24000-M $\mathrm{M}_{\mathrm{r}}$ GTP-binding signal described in the earlier work.

Vesicles that contain GLUT4 also contain Rab4 but for this GTPase a decrease concomitant with GLUT4 was observed after insulin treatment. We therefore suggest that at least two members of the Rab family, Rab4 and Rab11, participate in GLUT4 trafficking and that these proteins exert different functions. This notion would fit to a model in which Rab4 mediates the endocytosis of GLUT4 [18, 19, 20], whereas Rab11 participates in the insulin-regulated exocytosis and sorting of the transporter from the endosomal/recycling compartment. Several lines of evidence support this assumption. Firstly, a documented function of Rab11 consists in controlling vesicle trafficking through the recycling endosome to the plasma membrane [33-36] and we show here the insulin-mediated redistribution of Rab11 to the plasma membrane. Secondly, the abundance of Rab11 in the GLUT4-containing vesicles increases in response to insulin making it likely that Rab11 participates in 
A
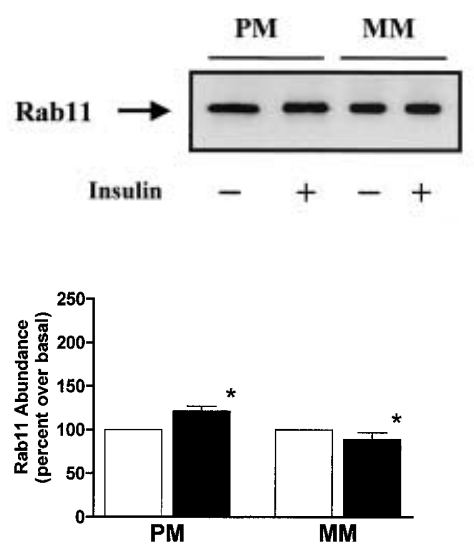

Fig.5A, B. Effect of insulin on the subcellular localization of Rab11 in obese ( $f a / f a)$ Zucker rats. A Subcellular fractions were prepared from cardiac ventricle of basal and insulintreated Zucker rats. $20 \mu \mathrm{g}$ of plasma membranes (PM) and microsomal membranes (MM) were analysed by SDS-PAGE followed by immunoblotting for Rab11. Bands were detected by using ECL system and LUHI Imager analyser. Quantification of western blots was done as described in Figure 3. Data are mean values \pm SEM of three separate experiments. ${ }^{*} p>0.05$. $\square$ basal, $\square$ insulin. B GLUT4-containing vesicles were immunoisolated from microsomal membranes of cardiac ventricular tissue of basal and insulin-stimulated Zucker rats. Microsomal membranes $(20 \mu \mathrm{g})$ obtained from basal hearts were used as a control. Samples were electrophoresed and immunoblotted for GLUT4 and Rab11. Representative experiments out of four are shown. Quantification of western blots was done as described in Figure 3. Data are mean values \pm SEM. $* p>0.05$. Glut4, $\mathbb{R}$ Rab11

the process of membrane docking and fusion. A Rab protein is required for the assembly of the SNARE complex in yeast [44] and Rab11 was found to co-localize with VAMP-2 and SCAMPS in tubulovesicles of gastric parietal cells [45], two proteins also present in the GLUT4-containing vesicles [2]. We further show that in parallel to Rab11, Akt-2 is recruited to the vesicles containing GLUT4 in response to insulin confirming very recent studies on isolated adipocytes $[9,12]$. Thus, we show here that insulin signalling to the vesicle containing GLUT4 is coupled to the specific recruitment of Rab11. Notably, Akt-2 was shown to phosphorylate component proteins of the GLUT4containing vesicles including a protein with a molecular mass of $25000 \mathrm{M}_{\mathrm{r}}$ [12]. It can be speculated that this protein is Rab11, which then serves to couple the insulin signalling cascade to the membrane docking event of the GLUT4-containing vesicles. If this is the case, Rab11 must be considered as a central element of the GLUT4-trafficking machinery.

We also found Rab11 in GLUT4-containing vesicles obtained from obese Zucker rats. Insulin was, however, completely unable to alter the cellular local-
B
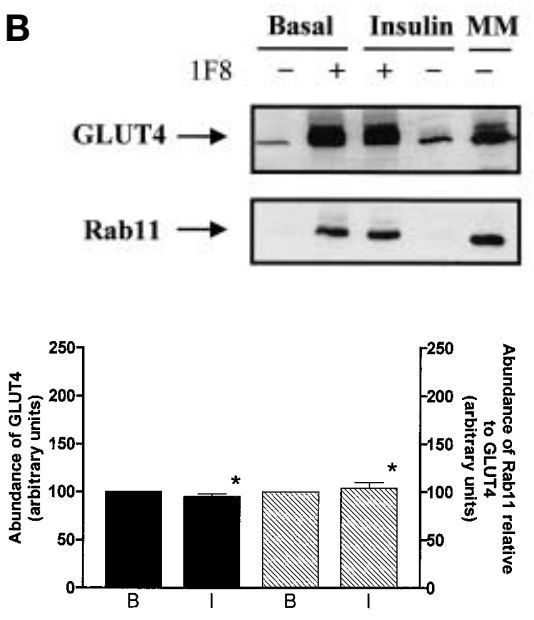

isation of Rab11 in these animals, most likely reflecting defective insulin signalling to Rab11. Multiple defects of the insulin signalling cascade have been described in earlier studies using obese rodent models of insulin resistance [46, 47]. For cardiac insulin resistance, our laboratory has recently reported the hyperphosphorylation of insulin receptor substrate-1 (IRS-1) on Ser/Thr coupled to a defective activation of PI 3-kinase [48], making it likely that Rab11 represents a downstream target of insulin-activated PI 3kinase. Consistently, earlier work has shown that insulin stimulates the guanine nucleotide exchange on Rab4 through a PI 3-kinase-dependent signalling pathway [49].

We report that Rab11 is an insulin-sensitive companion protein of GLUT4. The data support a model in which Rab11 is recruited from the endosomal compartment to the exocytotic GLUT4 pool. We suggest that Rab11 must be considered as an element of the GLUT4-trafficking machinery.

Acknowledgements. This work was supported by the North Rhein-Westfalen Ministry of Science and Research, the Ministry of Health, the German Research Foundation (SFB 351, C2), European Union COST Action B5 and BIOMED Concerted Action 3084. The excellent technical assistance of H. Müller is gratefully acknowledged.

\section{References}

1. Kandror KV, Pilch PF (1996) Compartmentalization of protein traffic in insulin-sensitive cells. Am J Physiol 271: E1-E14

2. Rea S, James DE (1997) Moving GLUT4: the biogenesis and trafficking of GLUT4 storage vesicles. Diabetes 46: 1667-1677

3. Cain CC, Trimble WS, Lienhard GE (1992) Members of the VAMP family of synaptic vesicle proteins are components of glucose transporter-containing vesicles from rat adipocytes. J Biol Chem 267: 11681-11684

4. Kandror KV, Yu L, Pilch PF (1994) The major protein of GLUT4-containing vesicles, gp 160, has aminopeptidase activity. J Biol Chem 269: 30777-30780 
5. Heller-Harrison RA, Morin M, Guilherme A, Czech MP (1996) Insulin-mediated targeting of phosphatidylinositol 3-kinase to GLUT4-containing vesicles. J Biol Chem 271: 10200-10204

6. Lin B-Z, Pilch PF, Kandror KV (1997) Sortilin is a major protein component of GLUT4-containing vesicles. J Biol Chem 272: 24145-24147

7. Morris NJ, Ross SA, Lane WS et al. (1998) Sortilin is the major $110-\mathrm{kDa}$ Protein in GLUT4 vesicles from adipocytes. J Biol Chem 273: 3582-3587

8. Martin LB, Shewan A, Millar CA, Gould GW, James DE (1998) Vesicle-associated membrane protein 2 plays a specific role in the insulin-dependent trafficking of the facilitative glucose transporter GLUT4 in 3T3-L1 adipocytes. J Biol Chem 273: 1444-1452

9. Calera MR, Martinez C, Liu H, Jack AK, Birnbaum MJ, Pilch PF (1998) Insulin increases the association of Akt-2 with Glut4-containing vesicles. J Biol Chem 273: 7201-7204

10. Volchuk A, Mitsumoto Y, He L, Liu Z, Habermann E, Klip A (1994) Expression of vesicle-associated membrane protein 2 (VAMP-2)/synaptobrevin I and cellubrevin in rat skeletal muscle and in a muscle cell line. Biochem J 304: 138-145

11. Olson AL, Knight JB, Pessin JE (1997) Syntaxin 4, VAMP2 and/or VAMP3/cellubrevin are functional target membrane and vesicles SNAP receptors for insulin-stimulated GLUT4 translocation in adipocytes. Mol Cell Biol 17: 2425-2435

12. Kupriyanova TA, Kandror KV (1999) Akt-2 binds Glut4containing vesicles and phosphorylates their component proteins in response to insulin. J Biol Chem 274: 1458-1464

13. Novick P, Brennwald P (1993) Friends and family: the role of the Rab GTPases in vesicular traffic. Cell 75: 597-601

14. Zerial M, Stenmark H (1993) Rab GTPases in vesicular transport. Curr Opin Cell Biol 5: 613-620

15. Cormont M, Tanti J-F, Zahraoui A, Van Obberghen E, Tavitian A, Le Marchand-Brustel Y (1993) Insulin and okadaic acid induce Rab4 redistribution in adipocytes. J Biol Chem 268: 19491-19497

16. Vollenweider P, Martin SS, Haruta Tet al. (1997) The small guanosine triphosphate-binding protein Rab4 is involved in insulin-induced GLUT4 translocation and actin filament rearrangement in 3T3-L1 cells. Endocrinology 138: 4941-4949

17. Shibata H, Omata W, Suzuki Y, Tanaka S, Kojima I (1996) A synthetic peptide corresponding to the Rab4 hypervariable carboxy-terminal domain inhibits insulin action on glucose transport in rat adipocytes. J Biol Chem 271: 9704-9709

18. Cormont M, Bortoluzzi M-N, Gautier N, Mari M, Van Obberghen E, Le Marchand-Brustel Y (1996) Potential role of Rab4 in the regulation of subcellular localization of Glut4 in adipocytes. Mol Cell Biol 16: 6879-6886

19. Dransfeld D, Uphues I, Sasson S, Schürmann A, Joost H-G, Eckel J (1999) Regulation of subcellular distribution of GLUT4 in cardiomyocytes: Rab4A reduces basal glucose transport and augments insulin responsiveness. Exp Clin Endocrinol Diabetes 108: 26-36

20. Mora S, Monden I, Zorzano A, Keller K (1997) Heterologous expression of rab4 reduces glucose transport and GLUT4 abundance at the cell surface in oocytes. Biochem J 324: 455-459

21. Uphues I, Kolter T, Goud B, Eckel J (1994) Insulin-induced translocation of the glucose transporter GLUT4 in cardiac muscle: studies on the role of small-molecularmass GTP-binding proteins. Biochem J 301: 177-182
22. Uphues I, Kolter T, Goud B, Eckel J (1995) Failure of insulin-regulated recruitment of the glucose transporter GLUT4 in cardiac muscle of obese Zucker rats is associated with alterations of small-molecular-mass GTP-binding proteins. Biochem J 311: 161-166

23. Kikuchi A, Yamashita T, Kawata M et al. (1988) Purification and characterization of a novel GTP-binding protein with a molecular weight of 24,000 from bovine brain membranes. J Biol Chem 263: 2897-2904

24. Ohmori T, Takeyama Y, Ueda T et al. (1990) Purification an characterization of a novel GTP-binding protein with a Mr value of 24,000 from rat liver. Biochem Biophys Res Commun 169: 816-823

25. Russ M, Wichelhaus A, Uphues I, Kolter T, Eckel J (1994) Photoaffinity labelling of cardiac membrane GTP-binding proteins in response to insulin. Eur J Biochem 219: 325-330

26. O'Farrell PH (1975) High resolution two-dimensional electrophoresis of proteins. J Biol Chem 250: 4007-4021

27. Immler D, Gremm D, Kirsch D, Spengler B, Presek P, Meyer HE (1998) Identification of phosphorylated proteins from thrombin-activated human platelets isolated by two-dimensional gel electrophoresis by electrospray ionization-tandem mass spectrometry (EMI-MS/MS) and liquid chromatography-electrospray ionization-mass spectrometry (LC-ESI-MS). Electrophoresis 19: 1015-1023

28. Eng J, McCormack AL, Yates JR 3rd, (1994) An approach to correlate tandem mass spectral data of peptides with amino acid sequences in a protein database. J Am Soc Mass Spectrom 5: 976-989

29. Yates JR 3rd, Eng J, McCormack AL, Schieltz D (1995) Method to correlate tandem mass spectra of modified peptides to amino acid sequence in the protein database. Anal Chem 67: 1426-1436

30. Kolter T, Uphues I, Wichelhaus A, Reinauer H, Eckel J (1992) Contraction-induced translocation of the glucose transporter Glut4 in isolated ventricular cardiomyocytes. Biochem Biophys Res Commun 189: 1207-1214

31. Laemmli UK (1970) Cleavage of structural proteins during the assembly of the head of bacteriophage T4. Nature 227: 680-685

32. Munoz P, Mora S, Sevilla L et al. (1996) Expression and insulin-regulated distribution of caveolin in skeletal muscle. Caveolin does not colocalize with GLUT4 in intracellular membranes. J Biol Chem 271: 8133-8139

33. Ullrich O, Reinsch S, Urbé S, Zerial M, Parton RG (1996) Rab11 regulates recycling through the pericentriolar recycling endosome. J Cell Biol 135: 913-924

34. Ren M, Xu G, Zeng J, De Lemos-Chiarandini C, Adesnik M, Sabatini DD (1998) Hydrolysis of GTP on rab11 is required for the direct delivery of transferrin from the pericentriolar recycling compartment to the cell surface but not from sorting endosomes. Proc Natl Acad Sci USA 95: 6187-6192

35. Urbé S, Huber LA, Zerial M, Tooze SA, Parton RG (1993) Rab11, a small GTPase associated with both constitutive and regulated secretory pathways in PC12 cells. FEBS Lett 334: 175-182

36. Chen W, Feng Y, Chen D, Wandinger-Ness A (1998) Rab11 is required for trans-golgi network-to-plasma membrane transport and a preferential target for GDP dissociation inhibitor. Mol Biol Cell 9: 3241-3257

37. Baldini G, Hohman R, Charron MJ, Lodish HF (1991) Insulin and nonhydrolyzable GTP analogs induce translocation of GLUT 4 to the plasma membrane in alpha-toxinpermeabilized rat adipose cells. J Biol Chem 266: 4037-4040 
38. Doucet J-P, Pierce GN, Hertzberg EL, Tuana BS (1992) Low molecular weight GTP-binding proteins in cardiac muscle. Association with a $32-\mathrm{kDa}$ component related to connexins. J Biol Chem 267: 16503-16508

39. Uphues I, Chern Y, Eckel J (1995) Insulin-dependent translocation of the small GTP-bindung protein rab3C in cardiac muscle: studies on insulin-resistent Zucker rats. FEBS Lett 377: 109-112

40. Uphues I, Eckel J (1996) Insulin-dependent glucose transport in cardiac muscle of obese Zucker rats: Studies on the role of small GTP-binding proteins. Exp Clin Endocrinol Diabetes 104 [Suppl 2]: 111-112

41. Hori Y, Takeyama Y, Hiroyoshi M et al. (1996) Possible involvement of Rab11 p24, a ras-like small GTP-binding protein, in intracellular vesicular transport of isolated pancreatic acini. Dig Dis Sci 41: 133-138

42. Hashiramoto M, James DE (2000) Characterization of insulin-responsive GLUT4 storage vesicles isolated from 3T3-L1 adipocytes. Mol Cell Biol 20: 416-427

43. Kandror KV, Pilch PF (1998) Multiple endosomal recycling pathways in rat adipose cells. Biochem J 331: 829-835

44. Sogaard M, Tani K, Ye RR et al. (1994) A rab protein is required for the assembly of SNARE complexes in the docking of transport vesicles. Cell 78: 937-948
45. Calhoun BC, Goldenring JR (1997) Two Rab proteins, vesicle-associated membrane protein 2 (Vamp-2) and secretory carrier membrane proteins (SCAMPs), are present on immunoisolated parietal cell tubulovesicles. Biochem J 325: 559-564

46. Heydrick SJ, Jullien D, Gautier N, Olichon-Berthe C, Van Obberghen E, Le Marchand-Brustel Y (1993) Defect in skeletal muscle phosphatidylinositol-3-kinase in obese insulin-resistant mice. J Clin Invest 91: 1358-1366

47. Saad MJA, Araki E, Miralpeix M, Rothenberg PL, White MF, Kahn CR (1992) Regulation of insulin receptor substrate-1 in liver and muscle of animal models of insulin resistance. J Clin Invest 90: 1839-1849

48. Kolter T, Uphues I, Eckel J (1997) Molecular analysis of insulin resistance in isolated ventricular cardiomyocytes of obese Zucker rats. Am J Physiol 273: E59-E67

49. Shibata H, Omata W, Kojima I (1997) Insulin stimulates guanine nucleotide exchange on Rab4 via a wortmanninsensitive signalling pathway in rat adipocytes. J Biol Chem 272: $1542-1546$ 